\title{
Agenciar palavras, fabricar sujeitos: sentidos da educação inclusiva no Paraná
}

Organize words, fabricate subjects: understandings on inclusive education in the state of Paraná

\author{
Fagner Carniel $^{\star}$ \\ *Universidade Estadual de Maringá - Maringá, PR, Brasil \\ fcarniel@uem.br
}




\title{
Resumo
}

O texto aborda os usos políticos e pedagógicos de uma concepção de inclusão educacional que adquiriu proeminência na gestão pública da educação brasileira durante a primeira década deste novo milênio. Para tanto, lança mão de uma reflexão construída a partir da inserção como técnico do Departamento de Ensino Básico na divisão de sociologia e tomando como eixo de discussão a interlocução com uma profissional que participou ativamente da organização da Secretaria de Estado da Educação do Paraná entre os anos de 2003 e 2011. Desse modo, o objetivo desta análise não se refere às experiências de pessoas em fase de escolarização, mas ao projeto institucional que pretendeu inseri-las em categorias pedagógicas relativamente estáveis e passíveis de inclusão fomentando um processo de organização estatal com base na nomeação e normatização de sujeitos. Trata-se, portanto, de uma tentativa de apresentar as práticas de gestão e sua justificativa discursiva em relação ao multiculturalismo, destacando as prerrogativas da educação inclusiva para pessoas surdas.

Palavras-chave: inclusão; antropologia da deficiência; gestão educacional; políticas públicas.

\begin{abstract}
The text addresses the political and pedagogical uses of a conception of educational inclusion that has gained prominence in the public management of Brazilian education during the first decade of this new millennium. In order to do so, it uses an ethnographic reflection built as a public servant in the Department of Basic Education in the section of sociology and organizing the text around the interaction with a professional who participated actively in the organization of the State Secretariat of Education of Paraná between the years 2003 and 2011. Thus, the objective of this analysis does not refer to the experiences of people in schooling, but to the institutional project that wanted to insert them in relatively stable and inclusionable pedagogical categories producing state organization and departamentalization based on the nomination and normatization of subjects. It is, therefore, an attempt to present state practices as well as their discursive justification related to multiculturalism, giving special emphasis to the prerogatives of inclusive education to deaf people.
\end{abstract}

Keywords: inclusion; disability studies; educational management; public policies. 


\section{Introdução}

O ano letivo de 2009 estava apenas se desenhando quando a transferência para o Departamento de Educação Básica então aconteceu. Num piscar de olhos acabei deixando a docência para me acomodar em um escritório no segundo andar do prédio central da Secretaria de Estado da Educação do Paraná (Seed). A razão não poderia ser outra senão a do momento oportuno. Tudo ocorreu em menos de um mês. Assim que comecei a coletar os primeiros documentos e legislações que orientam a gestão regional da educação especial e da inclusão educacional de pessoas surdas, dando início à investigação que pretendia desenvolver junto ao Programa de Pós-Graduação em Sociologia Política da Universidade Federal de Santa Catarina (Carniel, 2013), topei com Bernardo num dos corredores da secretaria. ${ }^{1}$ Conversamos por cinco minutos. Ele procurava alguém para integrar a equipe de sociologia e disse que gostaria de contar com minha formação acadêmica e profissional. Levei um susto. Na época não tinha a menor pretensão de largar o colégio onde atuara por quase dois anos e ingressar em um cargo burocrático na rede estadual de ensino, mas as condições eram realmente tentadoras -20 horas semanais e disponibilidade para viajar, o restante do tempo poderia ser despendido na pesquisa. Voltei para casa naquela tarde calculando as vantagens da oferta.

Sabia que o trabalho seria menos desgastante e mais flexível do que aquele que desempenhava em sala de aula; isso sem mencionar o prestígio profissional de se trabalhar em uma Secretaria de Estado. Contudo, as desvantagens também pareciam grandes. Acabara de iniciar meu trabalho de campo e ambicionava desenvolver um estudo no Departamento de Educação Especial e Inclusão Educacional sobre os significados recentes que a perspectiva da inclusão vem imprimindo sobre a compreensão política e pedagógica da surdez e das pessoas surdas. Evidentemente não se tratava do mesmo departamento, tampouco estaria junto

1 Adoto neste texto certos procedimentos para resguardar as identidades públicas de meus interlocutores e minhas interlocutoras. Nesse sentido, além de alterar seus nomes, procurei "fundir" suas declarações em relatos que, nesse momento, provavelmente já são mais meus do que de quem os informou, pois a "infidelidade" da narrativa científica parece residir nesse fato que perpassa as práticas da interpretação: trata-se de um processo de recriação e readequação que, inevitavelmente, exige certa responsabilidade por parte do autor - o pré-projeto que orientou a condução desta investigação, bem como das entrevistas realizadas, foi cadastrado no Sistema Nacional de Informações Sobre Ética em Pesquisas com Seres Humanos (Sisnep) sob o código 0329.0.093.000-11, que corresponde ao Certificado de Apresentação para Apreciação Ética. 
às pessoas que pretendia entrevistar, mas a simples ideia de virar um funcionário da Seed parecia comprometer o andamento da investigação; como se a proximidade ou familiaridade produzida pelo exercício daquela função pudesse "contaminar" as informações adquiridas - essa vã esperança de controlar rigidamente os rumos do projeto, bem como garantir objetividade e assegurar certa "neutralidade" aos dados coletados em campo, frequentemente produz sentimentos que "amarram" o trabalho de campo em formas predeterminadas de observação.

O dia da transferência chegou logo e com ele a ansiedade de ter de "começar do zero". Sabia que seria necessário travar novas relações profissionais em um ambiente deveras diverso daquele a que estava habituado; e que precisava aprender em ritmo acelerado suas gramáticas próprias (técnicas, políticas e sociais) para desse modo construir meu próprio espaço de observação e interação. Mas não se pode fazer isso sem levar um leve "choque", sobretudo quando não há outro controle da situação senão aquele destinado aos iniciantes - a despeito de todo o conhecimento prévio que pudesse ter sobre essa organização estatal, a despeito das descrições e teorizações acerca do funcionamento da burocracia pública com que tivesse entrado em contato, comecei o trabalho de campo como um recém-chegado, solitário e desamparado; colocando-me diante da "cultura" estudada não mais como uma abstração acadêmica, palpável, manipulável, mas como algo contraditório, difícil de visualizar e de pouca serventia. ${ }^{2}$

Dessa forma, me lancei nas microrrelações que organizam a educação inclusiva no Paraná, dividindo a atenção entre o ofício de técnico pedagógico de sociologia e a atividade de campo; um aprendizado estruturado pela rotina mais ou menos fixa que defini: às $8 \mathrm{~h} 30$ me juntava às colegas de equipe para planejar e executar as ações estabelecidas pelo departamento; ao meio-dia o

2 Como já observou Roy Wagner (2010, p. 36-37) ao refletir sobre a atividade etnográfica, "se a cultura fosse uma 'coisa' absoluta, objetiva, 'aprender' uma cultura se daria da mesma forma para todas as pessoas, tanto nativos como forasteiros, tanto adultos como crianças. Mas as pessoas têm todo tipo de predisposições e inclinações, e a noção de cultura como uma entidade objetiva, inflexível, só poderia ser útil como uma espécie de 'muleta' para auxiliar o antropólogo em sua invenção e entendimento. [...] A relação que o antropólogo constrói entre duas culturas - a qual, por sua vez, objetifica essas culturas e em consequência as 'cria' para ele - emerge precisamente desse seu ato de 'invenção', do uso que faz de significados por ele conhecidos ao construir uma representação compreensível de seu objeto de estudo. O resultado é uma analogia, ou um conjunto de analogias, que 'traduz' um grupo de significados básicos em um outro, e pode-se dizer que essas analogias participam ao mesmo tempo de ambos os sistemas de significados, da mesma maneira que seu criador". 
trabalho minguava anunciando o horário do almoço, às vezes incluindo algum tipo de observação; por volta das $13 \mathrm{~h} 30$ ou 14h encerrava minhas obrigações e caminhava até a biblioteca ou a cantina para retomar a pesquisa; deixava para marcar entrevistas ou circular pelos departamentos depois das $15 \mathrm{~h} 30$, quando minha presença parecia criar menos embaraço ou perturbações para as pessoas; tudo isso costumava durar até as $18 \mathrm{~h}$, momento em que a secretaria sempre se esvazia. É evidente que todo tipo de circunstância - reuniões, oficinas, cerimônias, viagens - interrompia esse dia a dia. Mesmo assim, eu me aferrei a ele nos primeiros meses, especialmente para driblar as frustrações de "não estar chegando a lugar algum", nem como pesquisador, tampouco como técnico.

É difícil dizer até que ponto as duas tarefas estiveram separadas; constantemente tive a sensação de estar desempenhando ambas as funções, pois os contatos estabelecidos e as informações conquistadas serviram sempre a esses dois mestres: o que se percebia como "interesse público" e o que era tratado como "interesse privado". Esta certamente é uma fronteira delicada para quem resolve se aventurar por uma Secretaria de Estado. O que você está fazendo? Qual a sua motivação? Quem é você? São apenas algumas das maneiras com que o poder estatal "interpela" seus funcionários e funcionárias, regulando as condutas para acomodá-las numa categoria estável e relativamente homogênea de burocracia. Isso não acontecia somente comigo, qualquer ação nesse prédio estava sujeita à vigilância dos princípios gerais que regem a forma jurídica da administração pública; não responder satisfatoriamente as normas de comportamento que modelam as ideias abstratas de legalidade, impessoalidade, moralidade, publicidade e eficiência evidentemente pode acarretar sérios problemas - e existiam dispositivos morais suficientes para isso.

Por isso, mesmo que a imersão nesse estabelecimento me garantisse uma vantagem comparativa na compreensão de suas rotinas, nunca tive acesso facilitado à vida "íntima" da secretaria. ${ }^{3}$ Era necessário explicar detalhadamente os

3 Ao problematizar o Estado, as políticas educacionais e a própria burocracia pública, não procurei realizar um estudo "sobre as políticas", mas "das políticas" e de seus momentos de significação. Para isto, entretanto, foi necessário desconstruir visões "essencialistas" (consideradas a priori) sobre as relações políticas e reconhecer, como adverte Mariza Peirano (1998, p. 22), a "suposição básica de que a categoria política é sempre etnográfica", pois resulta do próprio jogo das alteridades que compõe a pesquisa de campo. Isso me levou a crer que o fato de a política potencialmente estar em "todos" os lugares não significava que efetivamente estivesse; antes, tratou-se de uma possibilidade latente e não patente. 
motivos da pesquisa antes de conseguir entrar numa sala, pegar um documento, acompanhar uma reunião ou realizar uma entrevista - a simples permanência no prédio fora do horário de trabalho já causava muito desconforto. Entretanto, a proposta de estudar a marca deixada pelo ideário da inclusão da surdez nas recentes políticas de redemocratização do ensino básico muitas vezes seduzia as pessoas com a promessa (um tanto idílica) de que, talvez, esse trabalho particular pudesse contribuir com a "melhoria da educação" - uma possibilidade tentadora, sobretudo entre aqueles e aquelas que rejeitavam a alcunha de técnicos pedagógicos conferida pela burocracia pública e assumiam sua identificação com o universo escolar.

No começo não foi fácil para meus colegas e minhas colegas compreenderem em que consistia esse trabalho e muito menos levá-lo a sério. Embora a carreira no magistério exija um diploma superior, pressupondo alguma familiaridade com a atividade acadêmica, a tênue influência que os estudos etnográficos exercem sobre a prática e a organização política da educação se refletia no espanto das pessoas com os interesses que eu lhes apresentava. Numa ponta ficava a desconfiança das funcionárias que integravam, na época, a Área da Surdez no Departamento de Educação Especial e Inclusão Educacional - como declarou Lívia certa vez: “Observar!? Como assim observar? Não tem nada de mais no que a gente faz. Tudo está registrado. Se quiser saber como elaboramos nossas ações é só perguntar que eu te mostro. Caso contrário vai ficar aquela impressão de que você está nos vigiando." Na outra, a perplexidade dos 52 entrevistados e entrevistadas - a rede inteira de contatos e informantes que fui formando entre maio de 2009 e março de $2011^{4}$ - que invariavelmente vinham com perguntas acerca da delimitação, objetividade e legitimidade da pesquisa: "Mas você não quer estudar a inclusão educacional de pessoas surdas? Então, por que se importa com o que acontece nas outras áreas?"; "Vai estudar as pessoas surdas ou os funcionários da secretaria?"

4 Durante todo o período em que realizei essa pesquisa procurei agendar entrevistas com funcionários e funcionárias de todos os departamentos da Secretaria de Estado da Educação do Paraná. O roteiro de perguntas sempre variava de acordo com o conhecimento prévio que eu detinha sobre as pessoas, o cargo exercido por elas e os eventos que ocorriam no período. Contudo, sempre houve um sentido mais ou menos linear que orientou essas conversas: a tentativa de articulação entre a biografia (profissional e, por vezes, pessoal) e as atribuições, percepções e posições assumidas pelos entrevistados e entrevistadas - metodologia parcialmente inspirada nas propostas de Vieira (2013). 
De vez em quando surgia algo mais ríspido e direto como: "Bisbilhotar a vida alheia, esse método é novo para mim. Quero só ver como você vai transformar fofocas em provas científicas!"; "Investigar as políticas educacionais de dentro do governo, dá para ser mais parcial do que isso?”; “Já pensou que irá escrever sobre seus próprios companheiros de profissão, ou vai faltar com a ética ou com a verdade."

No meio desse interrogatório, ancorava boa parte das minhas justificativas na possibilidade de compreender a atividade simbólica da secretaria vivenciando sua "intimidade cultural"; ou seja, o modo como cada pessoa significava suas ações diárias e atribuía sentidos práticos ao seu trabalho. ${ }^{5}$ Produzindo, a partir daí, um tipo de conhecimento interessado nos efeitos que a inclusão educacional gera em toda uma população "invisível" de "incluídos" e "incluídas" no ensino regular; mas também comprometido com quem gentilmente e voluntariamente abriu o seu cotidiano profissional para que pudesse adentrar na "caixa-preta" da educação especial no Paraná - aquilo que poderia ser denominado como uma "cultura organizacional" que anima e orienta a própria estrutura política, pedagógica e administrativa da Seed.

Portanto, é a essa "cultura" que me dirijo neste texto; ou ainda, às experiências prolongadas - impressões paulatinamente transformadas em "significados culturais", como pontua Roy Wagner (2010) - que tive com o trabalho rotineiro de quem manipula a burocracia para criar sentidos diversos sobre 0 discurso oficial da inclusão educacional. A intenção nunca foi outra senão a de compreender como se produziu, no Paraná, um espaço legítimo de enunciação da surdez como uma "minoria linguística". Um espaço que parece ter contribuído tanto para a implementação regional de uma categoria normativa de sujeito quanto para a invenção de uma gramática pedagógica particular que possibilitasse o seu agenciamento escolar. Tal movimento foi iniciado ainda na década de 1980, legitimado particularmente pela celebração jurídica de uma

5 Tal noção de "intimidade cultural" permitiu lidar com a multiplicidade de percepções acerca da intimidade social desse espaço burocratizado da educação pública, auxiliando, desse modo, a traduzir as relações de poder sem, entretanto, acioná-las como pontos de partida preconcebidos. Como propõe Michael Herzfeld (2008, p. 31), o conceito de intimidade cultural pode ser tomado como um "antídoto" ao formalismo institucional, pois tem a capacidade de exprimir "a tensão formal ou codificada entre a auto-representação oficial e o que se vai passando na privacidade da introspecção coletiva". 
série de declarações, convenções e tratados internacionais que organizaram as lutas e demandas dos diferentes grupos locais que reconstituíram a educação especial ao longo dos anos de 1990, e adquiriu novos contornos administrativos até finalmente se estabelecer, em 2008, com a promulgação da Política Nacional de Educação Especial na Perspectiva da Educação Inclusiva (Brasil, 2008) como umas das principais bandeiras ideológicas das reformas pedagógicas que marcaram a "década da educação" no estado.

Nesse sentido, este texto não tem a pretensão de descrever os arranjos complexos que constituem a secretaria e seus inúmeros mecanismos de regulação da educação pública; muito menos procura recompor seu universo material e simbólico numa espécie de cartografia da educação básica no estado. Trata-se, na verdade, de um esforço pontual, modesto, - uma "cartografia noturna", se preferirem - que objetiva refletir sobre como a educação especial se reposicionou no interior desse setor intermediário da burocracia estatal a partir da emergência do discurso institucional sobre a inclusão das "pessoas portadoras de necessidades educacionais especiais" no ensino regular. Um discurso que têm ativado, nos anos recentes, variadas maneiras de regulamentação da população surda no estado. Portanto, ao longo deste artigo procurarei de problematizar os paradoxos da representação de pessoas surdas na educação básica através da análise de práticas regionais de gestão pública da inclusão escolar.

A ideia inicial era apresentar uma visão sobre o modo como determinada concepção de inclusão educacional foi concebida e implementada no interior daquela secretaria durante a última década; ou melhor, demonstrar como a sua incorporação (política e administrativa) foi sendo construída pela adesão regional ao discurso da transnacional diversidade e do reconhecimento das diferenças culturais. Um movimento que ocorreu no Paraná entre os anos de 2003 e 2011, ao mesmo tempo em que "recontextualizou"6 o paradigma estatal da inclusão para acomodá-lo à perspectiva emergente do multiculturalismo na educação. Para isso, entretanto, os documentos não me bastavam; seria

6 Refiro-me a noção de "campo oficial de recontextualização", elaborada por Basil Bernstein (1996), para indicar o esforço institucional em localizar o discurso multicultural da inclusão no interior da educação especial, alterando significativamente o agenciamento das identidades pedagógicas tradicionalmente atendidas por essa modalidade da educação no estado. 
preciso dar "vida" a eles, explicitar como foram percebidos e gerenciados no interior da própria instituição.

Com tal preocupação em vista, uso como eixo do artigo uma entrevista com a então secretária da Educação do Estado do Paraná. E não foi nada fácil consegui-la. Tinha enviado inúmeras cartas de apresentação com longas justificativas e mobilizado todos os contatos de que dispunha. Mesmo assim, foram três meses de espera. Aguardei pacientemente até conseguir uma "brecha" em sua agenda. No dia 26 de novembro daquele ano me ligaram; teria 45 minutos. As páginas que seguem são uma tentativa de recuperar essa conversa e problematizá-la a partir das experiências que acumulei durante o trabalho de campo na Seed, ora como funcionário, ora como pesquisador, e que me permitiram acessar uma dimensão significativa do modo pelo qual o tema da inclusão educacional foi agenciado pela burocracia estatal na entrada deste novo milênio.

\section{Uma nova gramática humanitária para a educação?}

Esperava uma conversa bastante formal com a ex-professora que, como supunha, se tornara uma gestora política de carreira durante os dois mandatos do PMDB no governo do estado. Porém, logo que entrei em sua sala fui desarmado pela informalidade com que começamos a conversar. Liguei o gravador quando ainda estávamos em pé, ao lado de sua mesa, falando da recente emergência de diversas ações sociais e políticas voltadas para a inclusão educacional e sobre como a secretaria foi sendo reorganizada para se adequar a esse ideário:

No Paraná, nos últimos anos, temos tentado acompanhar um movimento que é nacional, mundial. Uma visão mais humanitária, mais diversa, sem tantos preconceitos; é realmente uma nova forma de ver as pessoas. Isto está posto na Unesco, na Unicef, nos grandes órgãos internacionais. Estava posto aqui no Brasil também no começo do nosso trabalho.

De saída, sua posição mostrava-se evidente e remetia a várias outras legislações, planos, declarações e tratados que também estavam sobre minha mesa de trabalho. Dispositivos normativos que meus informantes e minhas informantes indicavam como sendo "os principais documentos" que orientavam a 
incorporação da noção de inclusão e animavam as políticas educacionais no estado. ${ }^{7}$ Configurou-se, assim, uma malha jurídico-política favorável à enunciação da inclusão educacional nos mais variados estados do país.

Em cada um desses textos oficiais vemos a primazia da universalização da escolarização básica, da democratização do acesso, da satisfação das necessidades inerentes à permanência, da promoção da equidade e da qualificação dos sistemas de ensino passava pela possibilidade de lidar com aqueles e aquelas que são considerados como "excluídos" das redes escolares. Sujeitos que figuram como "outros" e "outras" das políticas educacionais e que não se encaixam nos padrões tidos como "normais" de aprendizagem. Segundo ela,

o Brasil começou a tratar essas minorias como um público que é diverso no país. Nós tínhamos uma ideia no passado que pensava o aluno como se fosse um ser único, todos iguais e sem lidar com as diferenças. Quando você começa a lidar com essas diferenças vai vendo que esses que não são tão iguais, os pobres, os diferentes, eles foram sendo excluídos. E para a gente alcançar a famosa igualdade de condições aqui no nosso estado, nós temos que tratar diferente aquele que é diferente.

Diferença, diversidade, disjunção. A conversa mal começara e já havia revelado algo que eu estava procurando, como hipótese de trabalho: uma indicação do processo monogenético que se funda em planos estatais de longo prazo e implica necessariamente uma noção do "outro". ${ }^{8}$ Alguém cuja existência não poderia mais se fixar no território "cômodo" do exótico, do distante, do marginal, mas que precisaria ser reconsiderada no "aqui mesmo" da educação pública. Ao ouvir as declarações da secretária, tentei acompanhar exemplos do que, para mim, expressavam a forma como a secretaria refazia sua unidade e administrava a heterogeneidade de experiências escolares.

7 Um discurso que se estabeleceu na administração da educação pública do país por meio da adesão à própria Declaração Universal dos Direitos Humanos, de 1948, para adquirir novos contornos com a Declaração Mundial sobre Educação para Todos, em 1990, e com Declaração de Salamanca, em 1994; declarações internacionais que haviam influenciado diretamente a Lei de Diretrizes e Bases da Educação Nacional, de 1996, e o Plano Nacional de Educação, de 2001.

8 Tal como demonstrado por Fabiola Heredia e Gabriel Casas (2017) ao investigar a constituição legal da figura do "menor" em princípios do século XX na Argentina. 
Um desses episódios ocorreu bem no meio do segundo semestre de 2009 e diz respeito às dificuldades práticas que as indeterminações nas vivências e experiências escolares podem acarretar no processo de fabricação dos "sujeitos da exclusão" - interferindo, portanto, diretamente no trabalho burocrático de quem agencia as categorias identitárias e manipula os discursos pedagógicos que deveriam orientar os processos de inclusão no sistema educacional paranaense. Embarquei nessa história na terça-feira de uma das semanas mais chuvosas daquele mês de outubro. Assim que cheguei ao departamento um envelope me aguardava. Dentro, somente o processo enviado pelo Núcleo Regional da Educação de Pato Branco, ao sudoeste do Paraná, e o bilhete deixado por uma de minhas colegas de equipe. O bilhete dizia: "Querem um parecer nosso e pensei que você seria a pessoa mais indicada para fazê-lo. Desculpe!!!"

Quando terminei de ler o documento entendi o significado daquelas "desculpas" tão cheias de exclamações. Tratava-se de uma consulta formal que a técnica pedagógica Sheila, então coordenadora das equipes disciplinares daquele núcleo, pretendia fazer a respeito da possibilidade de matricular Cauã, um aluno kaingang, numa escola da rede regular de ensino. A justificativa para a mudança era a de que o menino perdera a audição depois de contrair rubéola e a escola indígena que costumava frequentar não tinha condições de oferecer intérpretes de língua de sinais. Isso gerava um duplo "problema" administrativo para "nós": por um lado, Cauã teria que ser deslocado da educação indígena à educação regular; por outro, a secretaria, através da educação especial, precisaria oportunizar meios (linguísticos e pedagógicos) para sua inclusão. Além disso, o processo ainda apresentava um caráter de "urgência", pois da sua resolução dependia a permanência da família no Programa Bolsa Família, do governo federal. ${ }^{9}$

Realmente não tinha a menor ideia de como proceder. Comecei a perguntar nas outras equipes e logo me dei conta do que "deveria" ser feito: um breve e objetivo parágrafo informando que o "nosso" departamento não tinha competência para solucionar aquele caso e que o núcleo em questão teria que recorrer

9 O Programa Bolsa Família, criado pela lei $n^{\circ}$ 10.836, de janeiro de 2004 (Brasil, 2004), tornou-se um dos principais programas que o Ministério do Desenvolvimento Social e Combate à Fome implementou para compor o conjunto de estratégias que integram as políticas relacionadas ao Fome Zero. 
a outros departamentos, coordenações ou mesmo secretarias. Provavelmente adotaria esse encaminhamento se o conteúdo do documento não despertasse especial interesse à minha pesquisa - ou ainda se o volume de trabalho naqueles dias não me permitisse considerar tal opção. Todavia, como a curiosidade pela resolução do caso "falou mais alto", decidi levá-lo adiante. Rapidamente passei a mão no telefone e pedi auxilio a Lívia, uma conhecida que respondia pela Área da Surdez na Seed. Queria saber como o Departamento de Educação Especial e Inclusão Educacional trataria o processo. Após explicar a história, escutei uma resposta contundente: "Não temos o que fazer a não ser tratar de nos desresponsabilizar." Houve um breve silêncio e, então, ela justificou: "Veja bem, se a própria pessoa do núcleo, que conhece a realidade da região, está segura do melhor procedimento e quer apenas um respaldo para matriculá-lo numa escola regular, não seremos nós a interferir nessa decisão."

Tal posição (contraditória e esquiva) não diferiu em nada do que escutara de alguns colegas minutos antes; entretanto, não podia ficar apenas nisso. Retruquei perguntando se não seria possível procurar uma escola especial, quem sabe um colégio para pessoas surdas que também oferecesse o ensino fundamental. Para mim tudo parecia muito "evidente" até esse momento; pelo menos até Lívia começar a me mostrar quão "complicada" a situação realmente poderia se tornar. Calmamente, ela disse: "Sei que você ficou sensibilizado com a história do Cauã. Todos nós ficamos. Mas nossa equipe simplesmente não pode se posicionar." Os argumentos que ela utilizou naquela ocasião foram os seguintes: "Primeiramente, o processo não foi encaminhado para cá, e se não o foi provavelmente é porque essa não é a vontade da família"; "Por outro lado, o menino perdeu a audição, mas não conhece a língua de sinais, nem mesmo a língua portuguesa. Você já imaginou como ele, o intérprete e o professor iriam interagir? Então, com o restante da turma não seria diferente." O que Lívia estava tentando me dizer era que se a Área da Surdez assumisse a responsabilidade e colocássemos Cauã numa escola ou classe especial, ele permaneceria em uma condição de exclusão.

Aproveitei a conversa para perguntar que tipo de procedimento poderia ser adotado. Nesse caso, ela foi enfática: "Como ele não é surdo, não se reconhece assim, acho melhor você tentar ver com o pessoal da educação indígena. Na verdade, são eles que têm de responder por isso." Sem titubear, subi as escadas em direção ao terceiro andar, onde se localizava o Departamento 
da Diversidade, e comecei a procurar pela sala da Coordenação de Educação Indígena. Beatriz, uma das técnicas que estava presente, me atendeu com certa indignação: "É curioso essa sua conhecida jogar toda a responsabilidade para nós. A partir do momento em que o menino perdeu a audição, penso que ele passa a ser enquadrado como um aluno com necessidades educacionais especiais." Minha reação de desconforto com a declaração deve ter sido tão evidente que ela não tardou a se explicar: "Veja, a constatação da surdez obriga o Estado a oferecer um atendimento especializado. Claro, sem que para isso tenha que se desligar da escola indígena. Mas foi bom você ter vindo aqui. Eu não estava sabendo da situação."

Na manhã seguinte Beatriz me procurou para dizer que já tinha conversado com Sheila e que elas chegaram a um consenso: "A convenci de que o menino deveria permanecer matriculado na escola indígena. Porém, o DEEIN [Departamento de Educação Especial e Inclusão Educacional] vai ter que oferecer um atendimento especializado em contraturno. Agora, acho que tudo vai se resolver." ${ }^{10} \mathrm{Na}$ hora não pude esboçar reação alguma, a não ser agradecer sua atenção e reencaminhar o processo para a Área da Surdez; mas sabia que tinha colocado Lívia "numa fria". Antes de ir "acalmá-la", resolvi ligar para Sheila e compreender o que exatamente havia sucedido. Conforme ela narrou pelo telefone: "É uma história bem complicada. O Cauã não consegue acompanhar a escola [indígena] porque não está escutando mais nada. Aí, a família, vendo a situação, está deixando ele na estrada. Isso já tem quase dois meses." Depois de alguns minutos, ela desabafou:

Tenho um relatório para entregar ao ministério [do Desenvolvimento Social e Combate à Fome] e se enviar do jeito que está a família toda corre o risco de perder o benefício. Por isso pensei em mudar o garoto de escola para tentar justificar as ausências. Só que a Beatriz acha melhor não mudar porque o menino não pode ser desligado da sua comunidade. Disse para encontrar um Centro de

10 Na época, essa exigência técnica por "atendimento especializado em contraturno" estava respaldada particularmente na Resolução CNE/CEB n 4, de 2009, que instituiu "novas" diretrizes operacionais para o Atendimento Educacional Especializado (Brasil, 2009). Tratava-se de uma ação que já havia sido proposta pela própria Constituição Federal de 1988, em seu artigo 206, e retomada por quase todos os documentos oficiais dedicados à educação especial que a sucederam. 
Atendimento [Especializado]. Já tinha falado com o Marcos [representante da educação especial daquele núcleo], mas ele falou que não era possível. Agora não sei mais o que fazer. Tenho até sexta-feira para conseguir uma boa justificativa, mas sabe como funciona a burocracia pública, não é?

Desci as escadas para encontrar Lívia antes que ela fosse informada por outra pessoa sobre o ocorrido. Quando lhe dei a notícia, não posso dizer que ficou satisfeita; porém, como me incumbiu em auxiliá-la, nossa relação pôde ser "reatada". Para ela, como já havia tentado me explicar no dia anterior, acionar o Centro de Atendimento Educacional Especializado daquela região não era uma opção: "Esse é um caso da área da saúde e não exatamente da educação." Portanto, pretendia mobilizar o técnico Marcos para introduzir "aos poucos" Cauã na comunidade escolar surda mais próxima de onde ele residia. O que Lívia estava imaginando era que: "O menino poderia aprender língua de sinais e, quem sabe, se torna um surdo - aí é outra história." Por isso, me incumbiu apenas de procurar alguém de uma das escolas regulares de Pato Branco que pudesse acompanhar Cauã durante as "visitas". No dia seguinte consegui contatar a direção de uma escola e utilizei toda a autoridade que o processo encaminhado pelo Núcleo Regional e um cargo no Departamento de Educação Básica poderiam me conferir. Depois de quase meia hora ao telefone, consegui "solicitar" que alguém o acompanhasse periodicamente. Aliviado, liguei para o ramal da Área da Surdez naquele mesmo instante e contei a novidade. Do outro lado da linha, Lívia agradeceu o empenho e disse que o caso havia sido resolvido. Segundo ela, decidiram que, de 15 em 15 dias, Marcos iria até a escola encontrar Cauã e o levaria para conhecer alguns colégios para pessoas surdas em Pato Branco para ver se (com sorte) ele começaria a aprender alguns sinais.

Pronto! O corpo burocrático da secretaria havia "solucionado" o conflito instaurado pelo "problema da deficiência". Sei que pode parecer uma piada de mau gosto. Entretanto, entendo que demos tudo de nós naqueles dois dias para produzir esse desfecho certamente precário e provisório. Nunca chegamos conhecer Cauã, sequer possuíamos conhecimentos superficiais sobre o grupo kaingang do qual fazia parte; tudo o que tínhamos era um processo, que criou a própria realidade abstrata do conflito e a urgência em enquadrá-lo dentro de uma modalidade "adequada" de ensino. Nesse sentido, não 
era como se não estivéssemos diante de uma questão pedagógica, mas a partir da secretaria não tínhamos outros meios senão vivenciá-la com certa "indiferença" administrativa. Afinal, como contou a secretária em sua entrevista,

sei que o seu interesse é pela educação especial, mas para te falar desse segmento eu preciso falar de outras tantas minorias que também foram ou estão descartadas desse bem cultural que é a educação. Por exemplo, a questão dos indígenas que nós tínhamos uma exclusão muito grande de acesso, permanência e qualidade; dos quilombolas que nem conhecíamos até 2004; os ilhéus são outro caso desses - nós descobrimos várias ilhas que não tinham escolas, as pessoas moravam lá a vida inteira sem ter escola. Eram minorias invisíveis para essa sociedade e que nós acabávamos descobrindo por uma razão ou por outra [...] famílias, vilas, distritos onde as pessoas não tinham escola. Comunidades de agricultores sem terra e alguns movimentos sociais ligados aos sem-terra, assentamentos novos, enfim. Eram comunidades que no processo de constituição do Brasil se tornaram pobres, que moravam em locais distantes, normalmente de famílias não letradas, que não tinham no seu processo civilizatório a educação como um bem porque isso não foi apresentado a elas.

Nesse sentido, a entrevista enveredou pela perspectiva das "minorias" que poderiam encontrar sua "redenção" através das lupas aguçadas do serviço público. Sujeitos ordenados e classificados em categorias educacionais que impedem a completa fragmentação do público escolar ao mesmo tempo em que produzem uma paisagem multicultural para esse sistema local de ensino. Tal maneira de "administrar a diversidade", como já observou Henry Giroux (2003, p. 75-83) ao analisar o contexto norte-americano da década de 1990, tem produzido contemporaneamente "políticas de reconhecimento" de grupos sociais que, explícita ou implicitamente, deixaram de "conectar as diferenças culturais às relações de poder". Desse modo, o autor observa a recente emergência de uma concepção do "multiculturalismo estatal" que, justamente por ser "centralmente representacional e abstratamente teórica", neutraliza os projetos culturais "dentro da lógica da inclusiva, mas homogênea, da assimilação".

Comecei a perceber essa forma estatal de administrar a diversidade e o multiculturalismo para promover o acesso à escolarização pública em diferentes momentos daquela entrevista. A secretária mencionou pessoas hospitalizadas, 
em privação de liberdade, jovens "nem-nem" (que nem trabalham nem estudam), pessoas analfabetas idosas - diversos grupos demandando atendimento específico - para relatar: “Com esse quadro trágico, que na realidade é um quadro de acesso, nós fomos criando várias políticas e institucionalizamos algumas coordenações, alguns departamentos específicos para trabalhar esse nosso princípio maior que é o da educação como um direito."

A população surda, meu efetivo foco de interesse durante a investigação que realizei naquele período (Carniel, 2013), ou qualquer outro coletivo atendido pela educação especial, não ganhou destaque no rol de alteridades elencadas pela secretária na ocasião. Entretanto, o que tinha me preocupado no curso da realização da entrevista já não parecia ter tanta importância depois de perceber, inspirado por Heredia e Casas (2017, p. 61-63, tradução minha), como a "conformação de novas categorias sociais resultam em novas administrações estatais com funções diferenciadas [...] para levar adiante a responsabilidade" que institui as próprias categorias. Ao ler e reler seus argumentos, percebi que a Área da Surdez também estava ali; talvez como uma parte "menor" ou como um apêndice do duplo processo de fabricação e exclusão educacional mantido pelos sistemas estatais de representação.

$\mathrm{E}$ isso ficou ainda mais evidente para mim quando lhe perguntei pelo modo como a Seed havia se organizado durante os últimos anos para identificar essas histórias e trajetórias invisibilizadas e como fazia para atender as pessoas, demandas e grupos sociais que não estavam incluídos na rede estadual de ensino. Ela retomou alguns exemplos para construir uma imagem sobre sua gestão, valorizando o ingresso de alunos ou alunas deslocados não apenas das instituições de ensino, como também dos próprios valores escolares que o Estado pretendia criar.

Cada segmento desses tem a sua história. Nós é que aproximamos essas histórias para compor agendas comuns de intervenção. Como te falei nem sabíamos quem eram os quilombolas até que vieram me contar uma história: alguém encontrou um ônibus escolar aqui perto, em Ponta Grossa [PR], onde sentavam ucranianos de um lado e remanescentes de escravos do outro; a pessoa se interessou e descobriu que o ônibus só deixava os ucranianos na escola, os quilombolas iam trabalhar na lavoura. Era uma questão nova para a gente e começamos um processo de descoberta. [...] Bem diferente era a educação indígena. No Brasil 
eles adquirem grande visibilidade lá na década de 1980, com a Constituição. Quando eu cheguei aqui na secretaria, em 2003, já estava tudo pronto. Existiam leis que respaldavam a educação indígena. Esse caso é parecido com o da educação especial. Eu tinha resoluções e até mesmo uma Secretaria de Educação Especial criada no MEC para me orientar. Um caso diferente foi o das pessoas no campo. O que existia era uma política de retirada para as cidades - a política que estava posta há uns 20 anos atrás. Inclusive quando se pensava no atendimento, foram fechando as escolas multisseriadas, que eram aquelas que atendiam mais próximo da comunidade, foram nuclearizando, trazendo essas pessoas para os setores mais próximos do urbano - eu costumo dizer que a escola foi substituída pelo transporte escolar [...]. Essa política foi revertida nos últimos anos pelo governo estadual e pelo governo federal com a criação das escolas no campo. Houve um movimento contrário e não havia resoluções apontando para isso. Nós começamos a criá-lo sem que houvesse nenhuma demanda dos movimentos. Na questão hospitalar é parecido. Tinha uma portaria, de 1960, que dizia que o aluno que estava em programas de saúde teria um atendimento especial e mais nada. Nós criamos instruções internas para dar esse atendimento. Portanto, eu penso que essas demandas apareceram de forma diferenciada. Algumas já prontas e outras que surgiram às vezes do nada.

A segurança demonstrada pela secretária ao transitar pelas trajetórias de lutas e construções de demandas educacionais de fato me surpreendeu. Durante a entrevista cheguei a considerar que a "agenda comum" para os processos inclusão, como ela expressava, poderia ser antes o efeito retórico de seu discurso enquanto gestora pública do que o indicativo de qualquer incompreensão a respeito das relações de poder que permeiam cada um dos coletivos administrados pelos departamentos e coordenações da secretaria. Por isso, lhe pedi mais detalhes sobre a relação que essas "demandas diferenciadas" teriam com a capacidade dos movimentos em impor suas posições políticas e pedagógicas.

Um dos casos em que eu visualizo claramente essa dificuldade em fazer valer seus direitos é o dos ilhéus. Eles nunca reivindicaram escola. Se eles tivessem a força de um MST, que reivindica tudo e mais um pouco, nós teríamos criado muitas escolas para eles. Só que eles estão do outro lado do continente, mal 
lembramos que estão lá. Foi preciso alguém ir até eles, alguém levantar, alguém falar com o governador, alguém falar com a secretária da Educação, para começar a surgir um movimento aqui, interno, de pessoas que são gestores, que ouviram e se sensibilizaram com a questão. Aí levam uma proposta que acaba tendo respaldo e você começa a sentir uma reivindicação que era do interior deles, mas que eles não viam formas de resolver, de impor políticas. É um processo bonito de descoberta de cidadania.

O exemplo era coerente. Contudo, a fala da secretária parecia atribuir demasiada centralidade ao Estado e ao seu corpo burocrático em absorver, identificar ou mesmo definir aquilo que as comunidades, grupos e movimentos sociais - rigorosamente organizados em suas "devidas" categorias pedagógicas - aspiravam da educação pública. Assim como argumenta Julian Simões (2017, p. 81) ao refletir sobre as categorizações das deficiências intelectuais: "Antes, o que se pode perceber é a enunciação das normas sociais que organizam grupos, que criam fronteiras, e no caso em questão que demarcam pessoas 'normais' e pessoas 'anormais'." Era como se não existisse qualquer outra mediação ao processo mais ou menos eficaz de implementação das políticas inclusivas. Isso começou a me incomodar de tal forma que não pude deixar de questionar a possível (ou provável) interferência de outros atores e atrizes, tais como comunidades acadêmicas, partidos políticos, setores da imprensa. Em sua resposta, ela foi enfática:

É claro que existem muitos setores da sociedade que demandam políticas nossas. Alguns bem-intencionados, outros nem tanto. Para você ter uma ideia, sempre que estou aqui [na secretaria] recebo pessoas com as mais diversas propostas ou reivindicações - são representantes de movimentos, empresas, sindicatos, profissionais de outras secretarias, estudantes, professores, diretores, famílias, muitas famílias. Todas essas pessoas sabem bem o que querem, mas dificilmente conseguem articular o que querem ao projeto maior que temos para a educação. Isso mesmo, nós temos um projeto, um caminho, não podemos aceitar qualquer coisa. Ontem, pela milésima vez, veio um representante de certa editora discutir o que ele julgava ser uma das necessidades para o ensino público do estado: a educação financeira. Queria porque queria que eu convencesse vocês, do Departamento de Educação Básica, a incluir esse conteúdo, e todos os materiais que 
o subsidiariam, nos currículos da educação básica. Não posso fazer isso. Não posso porque definimos nossas estratégias de modo democrático, em parceria com as escolas, com os professores, com as expectativas da comunidade escolar. E para isso temos os departamentos e as equipes, para filtrar essas expectativas e organizá-las de acordo com os princípios que defendemos. [...] Do meu ponto de vista, as equipes técnicas são a peça mais importante para a organização da educação pública no nosso estado. São vocês que fazem o trabalho de mediar essas demandas, de articulá-las aos nossos objetivos - quando eu digo vocês, estou incluindo o pessoal dos núcleos [Regionais de Educação]. Então, eu penso que são os próprios funcionários que realizam a ponte entre secretaria e universidades, entre secretaria e movimentos sociais. [...] O que eu faço é apenas a gestão disso tudo, priorizando sempre os mais desfavorecidos, aqueles que nunca tiveram uma chance de encontrar na educação um caminho para sua efetiva inclusão na sociedade.

Educação para todos! Um dispositivo político, normativo e organizacional pelo qual essas pessoas e coletivos se reconheceriam e seriam pedagogicamente reconhecidos. Depois de compreender o papel atribuído pela secretária à burocracia educacional, foi exatamente isso o que a sua perspectiva passou a me sugerir: uma "solução" educacional para as pessoas que estavam à margem da rede escolar. No entanto, tal discurso encobria outro problema: quem produz essas representações, quem detém o controle sobre elas? Não foi preciso muito esforço para compreender o papel da secretaria, das chefias e das equipes pedagógicas na identificação, agenciamento e estabilização dessas identidades educacionais. Segundo a própria entrevistada,

que pena que o Estado não é tão ágil para que esse processo se legitime rapidamente e não se perca. Eu tenho medo que algumas comunidades dessas, que acabaram de descobrir os seus direitos, que eles os percam na continuidade - a gente nunca sabe o que é certo ou incerto em termos dessas políticas públicas voltadas para toda a população. Isso sem falar naqueles grupos que nós nem conseguimos atender; os ciganos, por exemplo. Descobrimos que é uma comunidade nômade que passa pelo Paraná numa certa época do ano, que têm uma língua própria, tanto escrita quanto falada. Eles queriam iniciar um processo de alfabetização porque cerca de $90 \%$ deles são analfabetos - visto que eles 
não têm essa capacidade de aprender o português por conta da língua materna deles. Fomos buscar alguns elementos que nos subsidiassem. Uma das técnicas pedagógicas que estava envolvida na discussão foi à universidade para sondar umas possibilidades. Começamos um contato, fizemos alguns seminários, elaboramos um modelo itinerante de escola, parecido com aquele que implementamos para a educação no campo, as escolas itinerantes, mas dada a própria questão cultural deles nós não conseguimos reuni-los. Não demos uma resposta efetiva.

A compreensão da diversidade na unidade, frequentemente atualizada pelo que Peter McLaren (1997) já adjetivou como um processo "neocolonial" das "pedagogias de Estado", torna possível o reconhecimento do outro através da distância que os sujeitos tidos como diferentes mantêm daqueles que determinam e administram as partes que constituem a pluralidade social. Desse modo, seria possível produzir tanto uma posição universal privilegiada para quem reúne as diferenças culturais e sociais dentro de uma única imagem multicultural quanto a essencialização e homogeneização das pessoas desprovidas de poder nessa classificação hierárquica. Nesse contexto discursivo, a diferença surge como uma essência ou uma forma única que tende a apagar os traços de sua formação histórica. Assim, como afirma Homi Bhabha (2013, p. 64), "a universalidade, que paradoxalmente permite a diversidade, é aquela que mascara as normas etnocêntricas".

\section{Sobre o nominável e o abominável na inclusão contemporânea}

Integrar, incluir, adicionar, levar "para dentro" quem anteriormente ficava "de fora" da rede escolar. A educação moderna já fez e refez esse caminho incontáveis vezes (Larrosa, 2000). Todavia, algo parece ter sempre escapado aos modelos ordenadores. Os sistemas de ensino brasileiros, ao longo do século $\mathrm{XX}$, conviveram com diferentes lutas e demandas que progressivamente foram sendo institucionalizadas pelo campo comum da educação básica. Nada disso, contudo, serviu para solapar as dificuldades e até a ansiedade dos grupos, famílias e comunidades de alunos e alunas "excluídos" que viam na escola um único e viável caminho para transformação de sua condição social, cultural e 
econômica. Pelo contrário, o que se generalizou por todos os lados foi o que Pierre Bourdieu (1993, p. 484) já chamou de um "mal-estar crônico" instituído pela ideologia do "fracasso escolar".

Só que parece existir um elemento adicional na gramática pedagógica contemporânea; uma compreensão que reverberava na fala da secretária e parecia (auto)justificar o seu otimismo com relação à "melhoria" das condições gerais da educação no Paraná: a de que era preciso "tratar diferente aquele que é diferente". Mesmo se ocupando primordialmente de questões relativas ao acesso e permanência de estudantes paranaenses na rede pública de ensino, ela entendia que:

Trazer para dentro da escola, dar acesso, isso ainda não é o suficiente. O fato é que infelizmente a escola é uma instituição que promove a inclusão ao mesmo tempo em que pratica a exclusão. Isso ocorre porque ali dentro está a sociedade, uma sociedade que é preconceituosa, então ela acaba refletindo tudo isso sobre os alunos.

Desse modo, ela expressava uma posição emergente na gestão pública da educação na primeira década do século XXI - a percepção de que o simples "estar ali" das salas de aula, como proposto por várias concepções "integracionistas" que dominaram o debate educacional nacional nas décadas de 1970 e 1980 (Mendes, 2006), não garantia nenhuma participação efetiva àqueles sujeitos que configuram a categoria social dos "excluídos". Para ela, era preciso encontrar formas pedagógicas de assegurar não apenas a presença, mas também a participação das "minorias" na comunidade escolar, bem como a promoção de sua autonomia e autodeterminação. Assim, seguiu explicando como ajudou a reorganizar a secretaria para atender essa diversidade "desfavorecida", primeiro como superintendente e depois como secretária:

Nós tínhamos um quadro trágico aqui no estado. Por isso, quando chegamos nós queríamos dar mais, queríamos dar de forma diferente, com um atendimento diferenciado a estes que não tinham atendimento para que eles também pudessem se tornar iguais. O discurso parece meio contraditório, mas foi exatamente essa a proposta que implantamos aqui. Primeiro com a educação especial e na sequência veio a criação do Departamento da Diversidade. A partir daí a questão 
da inclusão ganhou corpo dentro da secretaria e cada departamento foi criando as suas diretrizes de trabalho.

Tal concepção organizacional não era estranha aos textos e documentos oficiais que meus informantes e minhas informantes utilizavam para legitimar suas ações na secretaria - uma forma perversamente ingênua, como sugere Catherine Walsh (2013), de reduzir toda a complexidade de formas de saber e de existir enquanto um movimento linear em direção à democratização dos sistemas escolares.

Evidentemente, histórias como a de Cauã não apareciam todos os dias nos bastidores da administração pública paranaense. Todavia, também não pude considerá-las como meros casos fortuitos ou episódicos, pois a maneira aventureira, para não dizer arriscada, pela qual lidávamos com elas informava justamente a existência de inconstâncias ou instabilidades no agenciamento dos sujeitos e dos objetos pedagógicos que representavam as partes constituintes da "diversidade educacional" no estado. E nada parecia desfigurar mais aquele ambiente profissional, tão seguro de sua autoimagem da reprodução de procedimentos predeterminados, ininterruptos, que se (dis)solvem no encadeamento de práticas racionalizadas de classificação dos saberes e das alteridades que integrariam a rede escolar, quanto a entrada de um corpo "estranho". Algo ainda indeterminado e que, para deixar de sê-lo, exigiria mudanças ou adaptações na prática cotidiana de quem organiza a educação pública.

De fato, tratava-se de uma tarefa extremamente difícil e para a qual nem sempre estivemos preparados ou motivados. Mesmo assim, não podíamos simplesmente ignorá-la, pois os conflitos pedagógicos representavam, em grande medida, o principal motivo pelo qual nós docentes - e não outros funcionários ou funcionárias públicas - estivemos à frente das atribuições técnico-pedagógicas dessa secretaria. Por isso mesmo, costumávamos encarar com certa "aflição" qualquer evento que escapasse à ordem dos elementos que constituíam a unidade do sistema educacional. Como se o nosso olhar estivesse tão habituado a procurar continuidades, a enquadrar os acontecimentos em uma mesma curva evolutiva, que nutríamos singular aborrecimento por tudo o que pudesse sugerir uma diferença radical em relação aos discursos já estabelecidos - particularmente, sobre aqueles discursos que informavam quem deveria ser incluído e onde ou como poderia ocorrer a inclusão. O problema é que, por 
mais que procurássemos evitá-las, tais descontinuidades insistiam em aparecer, ora explicitando nossa incapacidade em lidar com essas diferenças, ora exigindo outras tomadas de consciência sobre a complexidade dos processos de exclusão.

Sugerindo, assim, que o trabalho burocrático nos departamentos e coordenações permite compreender a secretaria como uma instituição plural e em constante transformação. Um local atravessado por uma infinidade de relações, lógicas e dinâmicas que acompanham as trajetórias profissionais (e pessoais) de seus atores e atrizes. Isso porque, como espero ter explicitado, convergiam nesse setor estatal formas simbólicas, perspectivas educacionais e modalidades de gestão e gerenciamento que, ao mesmo tempo em que visavam reconstituir as experiências, saberes e subjetividades escolares a partir de modelos pedagógicos passíveis de inclusão, também eram simultaneamente reconstituídas por elas.

Tal observação, entretanto, antes mesmo de indicar uma "falha" ou incapacidade eventual, parecia confirmar a efetividade do argumento. A passagem do abominável para o nominável, do caótico ao ordenado, do excluído ao incluído. Sujeitos que apenas teriam sua diferença reconhecida, respeitada, tolerada, mediante a capacidade de se adequar ou hospedar certos princípios e valores nacionais ou transnacionais da educação. Outros e outras que seriam absorvidos pela linguagem burocratizada da educação e por seus sistemas de classificação; uma pluralidade de vivências unificadas pelo ensino regular, pelos currículos e materiais didáticos que, sob o pressuposto da igualdade, normalizam as diferenças em uma experiência comum de escolarização.

Acompanhei inúmeros eventos como esses naquele ano (Carniel, 2013). Seus relatos estavam espalhados entre as anotações dispersas que distribuí sobre a mesa de trabalho - eram notas sobre disputas em torno da incorporação dos conteúdos de história e cultura afro-brasileira nos livros didáticos da educação básica; tensões acerca da implementação da disciplina de ensino religioso nas escolas indígenas; ausência de consensos na elaboração de programas, cursos e eventos de formação docente; indeterminação na divisão das equipes; responsabilização dos departamentos ou coordenações para empreender uma ou outra ação. Em cada um desses casos as noções de diversidade e de multiculturalismo figuraram como termos capazes de administrar os conflitos e recriar uma imagem pedagógica que tudo alcança, captura, define e torna 
próprio - uma representação sólida, segura, entusiasmada com a dissolução das indeterminações e ambivalências do sistema educacional.

Só que a articulação entre o trabalho realizado pelo Departamento da Diversidade e aquele desempenhado pelo Departamento de Educação Especial e Inclusão Educacional nunca chegou a se efetivar nos ambientes profissionais que observei. Pelo contrário, cada equipe parecia se concentrar a tal ponto na especificidade de sua área que, na maioria das vezes, desconhecia o que ocorria no restante do estabelecimento.

Além disso, as pessoas com quem convivi naquela época, com poucas exceções, não se utilizavam dessa perspectiva multicultural da inclusão como um princípio único, coerente e estável; e mesmo quando as indagava diretamente suas respostas se alteravam tanto que era impossível atribuir critérios objetivos para estabelecer qualquer definição ou percepção mais geral. Por isso, atravessei a narrativa da secretária para lhe perguntar pela afinidade específica que a educação especial mantinha com a inclusão educacional e se essa incorporação teria modificado a relação desse departamento como os demais. Ela pensou um bocado antes de retroceder no tempo e afirmar que o Departamento de Educação Especial, quando fundado, atendia uma demanda social assistencialista e de apoio a instituições conveniadas, característica presente "até hoje", a ponto de interferir na denominação do órgão: "A princípio eu queria criar só um departamento de inclusão educacional. A resistência em manter a palavra educação especial e inclusão educacional foi do departamento porque eles não aceitavam entrar no conjunto de políticas que lidavam com a inclusão social."

Depois dessa declaração, a imagem harmoniosa de uma concepção política e pedagógica que teria sido ativada por sua gestão a partir da defesa de uma educação inclusiva começou a se desfazer. A conversa guinou, então, para as dificuldades enfrentadas por ela para impor sua proposta e controlar os rumos da educação básica enquanto um projeto coeso e integrado:

Foi uma luta para entender aquele professor [da educação especial] como um professor que tinha plano de carreira, que tinha que fazer capacitação, que tinha hora-atividade. Nem se pensava em hora-atividade, era outro segmento, era outro sujeito nessa história. Uma luta importante foi a da gratificação especial. Eu tirei essa gratificação. Por quê? Porque aquilo era visto mais ou menos como 
uma insalubridade. É verdade que são condições diferentes, não se pode ter 30 alunos na sala, às vezes têm que ter cinco, com um livro diferenciado, um quadro diferenciado. $\mathrm{O}$ trabalho muda, mas ainda são professores como todos os outros. [...] Isso tudo foi muito difícil de ser incorporado pelo departamento. Eu diria que hoje eles conseguem transitar mais facilmente com essa ideia, mas era um departamento que era um feudo à parte. Tudo era dividido assim: a resolução de distribuição de aulas, a gente fazia uma regra geral para o estado e outra para a educação especial. Eles não conseguiam entender a educação especial como parte de um mesmo princípio.

Mudar os departamentos para mudar as culturas escolares. Unificar o trabalho interno da instituição para que sua gestão pudesse exteriorizar um discurso, um único caminho que deveria ser percorrido por toda a rede de ensino. Conforme a secretária, esse foi o objetivo traçado para a educação especial, assim como para todos os atendimentos prestados pela secretaria. Ela pretendia modificar o comportamento daqueles e daquelas que representam a educação básica para modificar as próprias práticas de significação; reconfigurando, desse modo, os sistemas simbólicos da inclusão educacional no estado.

Tenho aqui vários departamentos e cada departamento é como um filho. Cada filho se mata pelo departamento dele e é difícil o trabalho coletivo. O Departamento de Educação Básica, por exemplo, se fecha na educação básica e no ensino regular. Quando digo: vamos discutir a diversidade. Vocês se fecham em copas. Quando vou para o Departamento da Diversidade não é diferente. Internamente eu percebo essa fragmentação. São rixas pessoais, corporativismos, entra de tudo nessa composição - quantos funcionários lá, quantos computadores para cá. [...] Hoje estávamos discutindo o ensino de nove anos. Chamei a pessoa responsável e chamei também o pessoal da educação indígena. Eles não conversaram. [...] Por um lado é muito bom, porque é importante a luta pelo que cada um acredita. Só que eu sou a secretária de Educação. Como é que eu faço? Como é que eu respondo a isso? Como é que vamos mudar a mentalidade nas escolas se nos mostramos divididos assim? Não dá. Tenho que ter uma resposta coletiva. Então, tento buscar no coletivo, na gestão e procurar trazer sempre o princípio maior. Isso me apaixona. Como é que você pensa o aluno da educação especial dentro do sistema educacional? Necessariamente você tem que sair do 
seu departamento. Tem que pensar isso numa estratosfera. Acontece que o dia a dia nem sempre permite que o funcionário veja isso de uma forma estratosférica. Ele acaba pensando apenas sobre o fazer dele. Portanto, a busca da unidade na diversidade é o grande desafio das nossas políticas educacionais.

De fato, me parecia um retrato impecável das disputas departamentais que presenciei durante minha passagem pela secretaria. Diante dele, a conversa mudou de tom. De entrevistador passei a entrevistado. Ela queria saber qual era minha impressão da secretaria, do Departamento de Educação Básica, das ações empreendidas naquele ano. Nesse ponto, me senti acuado e não consegui fazer nada além de adequar meu discurso para que ele soasse como se eu também fizesse parte do mesmo princípio, da mesma unidade projetada pela secretária e colocada para as pessoas que ela encarregou de administrar os diferentes espaços da educação pública no Paraná - mas não foi exatamente isso que vivenciei durante minha e pesquisa de campo.

As relações inconstantes que se tecem nos espaços íntimos da secretaria parecem ter o potencial de imprimir valores e perspectivas pessoais sobre o tecido material do poder público; isso porque elas fazem parte do dia a dia de funcionários e funcionárias que, antes mesmo de compartilharem conhecimentos e identidades corporativas, estão envolvidos por redes densas e dinâmicas de sociabilidades. Quem você conhece? Que tipo de informações consegue acessar? Quais são os recursos humanos e financeiros que pode ativar? O manejo desse repertório de contatos e possibilidades que cada pessoa acaba construindo concomitantemente com sua trajetória profissional certamente extrapola os sentidos imediatamente técnicos e objetivos do trabalho burocratizado, deixando um lastro de interesses e relações difusas na realização de suas atribuições. Isso ocorria por todos os lados, às vezes como forma de sobrevivência no cargo, em outros casos como tática de "distinção". Pouco importava. $\mathrm{O}$ fato era que quanto maior a capacidade de mobilizar sujeitos e conhecimentos no interior do campo educacional do Estado, com mais facilidade se podia jogar o jogo das relações sociais, administrativas e políticas na secretaria - e eram exatamente esses "jogos" que me deixavam entrever os usos "táticos" que se faziam das "estratégias" retóricas da educação.

A adesão a um ideal cultural estático e inquestionável - como nos eram apresentados os ideais de "qualidade" e "equidade" na educação - não apenas 
fundamentava as formas legítimas do debate, como também permitia e até encorajava a sua subversão. Isso ocorria porque a exteriorização do "interesse público" em uma gramática pedagógica apropriada proporcionava uma máscara que conferia notável liberdade aos indivíduos que sabiam empregá-la. Atores ou atrizes hábeis utilizavam-se dos códigos e ideologias estatais para obterem os resultados desejados; quem não detinha tal êxito acabava culpando o sistema, o Estado ou as políticas, e assim confirmando seu poder. A diferença nas performances sugere que as pessoas atuavam nessa esfera pública tendo em vista o seu passado, sua trajetória, sua familiaridade com os dispositivos e linguagem estatais; depositando esses "antecedentes" nas disputas políticas e semânticas que envolviam as tomadas de decisões. Só que nada disso seria evidente para quem apenas observa o Estado "de cima". As proximidades, agendas, informantes, afinidades, amizades, inimizades, tudo vazava por entre as brechas do discurso unânime da racionalidade administrativa enquanto eu tentava seguir os passos daqueles e daquelas que, como julgava, poderiam oferecer as "pistas" necessárias para compreensão da prática "oficial" da educação estadual de pessoas surdas.

Relendo a transcrição da conversa com a secretária, talvez pudesse (ou devesse) ter dito que compreendia o cuidado dela em realçar certo compromisso de sua gestão com a identificação de coletivos desfavorecidos e com a criação de modelos de ensino diferenciados para atendê-los - afinal, esse foi o papel que ela tomou para si durante aqueles anos. Porém, independentemente dos significados atribuídos à inclusão dos grupos excluídos do ensino público, o que me parecia estar em jogo não era um simples processo de delegação, denominação e descrição de alteridades educacionais que ocupariam o espaço discursivo da exclusão; antes, tratava-se da regulação e controle sobre os lugares para os quais a educação paranaense poderia olhar, se reconhecer e fixar seu público diverso.

Isso ficou evidente quando folheei os relatos das chefias dos departamentos e coordenações que entrevistei nessa mesma época; todas pareciam unânimes em indicar a reestruturação da educação básica e das escolas regulares, seus profissionais e currículos mínimos, como as principais frentes de trabalho da instituição. Além disso, a própria secretária, em um programa realizado pela TV Educativa poucas semanas antes, havia afirmado que "a maior conquista do governo" fora preparar a rede escolar para cumprir a Proposta de Emenda à 
Constituição $n^{\circ}$ 96, de 2003. Entusiasmada, ela falou às câmeras que o Paraná não precisaria esperar até 2011 para tornar obrigatório o ensino de 4 a 17 anos:

Ainda em 2010 o sistema estará organizado para receber todos esses alunos. [...] O investimento não foi apenas na infraestrutura. Fora as instalações, transporte escolar, merenda, livros didáticos, também houve um grande investimento na formação de professores, na elaboração de propostas pedagógicas e na gestão escolar. [...] Essa talvez tenha sido uma das maiores medidas educacionais dos últimos cem anos no Brasil.

É evidente que as motivações e objetivos de um discurso eminentemente político possivelmente fossem distintos daqueles que a fizeram participar da minha entrevista; mesmo assim, é interessante notar como o discurso da inclusão educacional oferecido pela secretária somente poderia se consolidar como o resultado, talvez final, de uma reestruturação e qualificação do próprio ensino regular. Esse seria considerado "o alicerce necessário para quase todas as linhas de ação" da Seed, como uma das técnicas pedagógicas que trabalhavam com a educação de jovens e adultos admitiu ao se referir à centralidade das Diretrizes Curriculares da Educação Básica (Paraná, 2008) no estado e dos livros didáticos públicos do Paraná na implementação das políticas federais para a área.

Naquele instante, ficou um pouco mais nítido para mim o lugar simbólico ocupado pelos diversos grupos sociais que configuravam a chamada educação especial e a educação para a diversidade no interior da secretaria. Eram sujeitos preconcebidos pelo trabalho ordenador de áreas entendidas ou planejadas como subcampos de uma espacialidade egocêntrica; especialidades ou especificidades de um discurso autocentrado em uma enorme imagem escolar: a da escola regular.

Desse modo, talvez seja possível dizer que uma parcela significativa daquilo que hoje entendemos por educação inclusiva no Paraná, para não falar em Brasil, ainda diz respeito ao processo de regularizar os sujeitos anteriormente tidos como irregulares, erráticos, desiguais, anormais, marginais; normalizar suas trajetórias estudantis a partir de um modelo comum que balizaria todo o processo de escolarização. Para isso, não importaria à gestão pública quais seriam os atendimentos diferenciados, as diferenças consideradas. $\mathrm{O}$ que 
efetivamente parecia ordenar e significar o agenciamento estatal era a atividade de reconhecer o destino, o projeto, o princípio que unificaria a multiplicidade, a pluralidade, a diversidade - ou, como já observou Carlos Skliar (2003, p. 71), "a persistente imagem do dentro e do fora que naturaliza o pensar, o olhar, o perceber o mundo, pois o torna idêntico à mesmidade”.

Assim, nasciam os grupos "absolutamente excluídos" e abrolhavam as propostas para transformá-los em "absolutamente incluídos", indicado o estabelecimento de uma categoria social binária e destituída de experiências pessoais. Uma categoria aparentemente capaz de apaziguar qualquer conflito, contradição ou indeterminação. ${ }^{11} \mathrm{E}$ o "sucesso" ou a efetividade dessa operação dependia da manipulação de corpos imaginários, da competência organizacional em impor um plano, um projeto, um futuro para pessoas que desejavam visibilidade. Essa habilidade, esperada dos técnicos e técnicas pedagógicos, não se media exatamente pelo que esses "outros" e "outras" da inclusão eram ou aspiravam a ser - pouco podíamos saber sobre essas pessoas se passávamos os dias encerrados no prédio que abrigava a secretaria -, mas pelo modo como emergiam no espaço público da educação e por aquilo que poderiam representar para quem detinha o poder de nomear ou deixar de nomear.

Outros e outras cuidadosamente pronunciados, quantificados, politicamente corretos, enunciados à distância, capturados pelo olhar estatizado do funcionalismo público até se tornarem (para nós) sujeitos da educação. Portanto, esse o jogo das identidades pedagógicas fabricadas com e através de um Estado indutor de categorias de sujeito - ou ainda, de "políticas identitárias", como argumenta Tomaz Tadeu Silva (2004) - acabou girando em torno da maior ou menor capacidade de as equipes ajustarem suas alteridades "excluídas" à (nossa) gramática multicultural da inclusão.

11 Mesmo tendo auxiliado a visibilizar grupos sociais e problemas educacionais invisíveis em outros momentos ou contextos da educação paranaense, o que permanecia oculto ou subterrâneo nesse trabalho local de ordenação das alteridades excluídas era o movimento de essencialização da própria exclusão. Normalizada e naturalizada pelo discurso da inclusão educacional, a exclusão parece ter deixado de figurar como uma relação constitutiva do processo educacional para ser identificada como um atributo inerente ao sujeito - a (sua) suposta "privação", atribuída (por nós) através das "faltas", "ausências" ou "deficiências" que representávamos por meio do (seu) corpo e da (sua) subjetividade como as marcas da exclusão educacional. 


\section{Incluir quem? Incluir onde?}

Passados alguns anos desde daquela conversa e de minha passagem pela secretaria, hoje consigo perceber um pouco melhor como nos bastidores da administração pública paranaense daquele do período realmente havia a vontade de produzir algo significativo em termos educacionais. Uma aposta política e pedagógica que envolveu a tentativa de se aproximar e de dialogar com grupos sociais até então marginalizados ou simplesmente excluídos por outras gestões desse sistema regional de ensino. A efetividade dessas ações, no entanto, como procurei demonstrar ao longo deste ensaio a partir da reconstrução narrativa de uma entrevista com a secretária geral da Seed, esteve sempre limitada pelas próprias perspectivas que as circunscreveram. Desse modo, qualquer desejo de "melhorar" a educação e de torná-la acessível para um contingente cada vez maior de pessoas acabou sendo condicionado aos instrumentos e aos pressupostos oferecidos por uma gramática normativa que esteve "presa" à armadilha desnecessária dos binarismos modernos - regular ou irregular, dentro ou fora, incluído ou excluído, nominável ou inominável.

Por conta disso, talvez, aquela gestão que se manteve no poder entre os anos de 2003 e 2011 no Paraná não tenha conseguido oferecer mais do que espaços reduzidos de atuação, através dos quais certos grupos sociais seriam convencidos (ou submetidos) a se constituir enquanto "sujeitos" da educação, nos dois sentidos da palavra. E para estabilizar essas práticas, certa noção de pessoas "excluídas" figurou como uma categoria suficientemente representativa e com o potencial político de unificar todas as "especialidades" pedagógicas agenciadas pelas equipes da Seed. Por intermédio dela, as atividades fragmentadas dos funcionários e funcionárias que se ocuparam em promover a "inclusão" puderam encontrar alguma coesão na espacialidade dominante das identidades pretendidas pela autoridade estatal. O que não significa, evidentemente, que os processos de exclusão sejam meros efeitos retóricos de discursos estatais. Pelo contrário, as distorções e hierarquias visibilizadas pelo corpo burocrático da secretaria eram reais - tão reais quanto as representações identitárias que foram criadas sobre elas. Só que a paradoxal indistinção com que se afirmou e praticou a inclusão dos indivíduos genéricos da exclusão - primeiro organizados em categorias particulares, depois agenciados em uma retórica comum - exigia uma dissimulação muito grande das possíveis (ou prováveis) 
ambivalências, contradições e hibridações implicadas na inclusão educacional. Afinal, a entrada de um sujeito aparentemente "estranho" ao processo de assimilação individual e de reconhecimento coletivo poderia simplesmente subverter a ordem traçada para a educação básica.

Pensando nesses problemas, cheguei à conclusão de que a secretária, meus colegas e minhas colegas de trabalho, eu mesmo enquanto técnico pedagógico, todos fomos perversamente indiferentes à irrupção de qualquer irredutibilidade ou imprevisibilidade que pudesse abalar a "virtuosa" configuração daquele sistema local de ensino. Não afirmo isso apenas porque o cotidiano da secretaria, vigiado, administrado e disciplinado por uma série de técnicas de controle e regulação burocrática, imputava a tarefa de fabricar ou manejar categorias identitárias coerentes com os objetivos traçados pelo poder público. Mas principalmente porque a consequência desse processo de regulamentação foi o desconhecimento ou a invisibilização de novas hierarquias ou subordinações que o Estado poderia impor. Portanto, visibilizar essa forma estatal de organização do poder na educação básica brasileira em um período de reforma educacional, como o que estamos vivenciando em 2017, me pareceu relevante, pois uma das tarefas politicamente mais desafiadoras para a antropologia da educação ainda parece ser a de desarmar as narrativas previamente estabelecidas acerca do outro.

Portanto, talvez não seja precipitado encerrar este texto constatando que a retórica educacional de nossos dias apresenta um discurso enganadoramente harmônico no que se refere às suas ações. Nas duas últimas décadas, as tecnologias de governo que gerenciam as ideias de diferença e multiculturalismo na educação brasileira migraram da integração à inclusão, da educação especial à regular, deixando cada vez mais para trás a imagem das pessoas "anormais", de que falou Michel Foucault (2001), para nomear cada um dos grupos excluídos dos projetos de modernização. Porém, quem são esses outros e outras de que tanto se ocupa a educação? Suas identidades "flutuam" por entre as mesas e escritórios das instituições de ensino até se fixarem num ou noutro documento oficial. Ao menos essa é a sensação que se tem quando pensamos o Estado "de cima": são identidades educacionais construídas como inovações por intermédio da atuação da burocracia pública; funcionários e funcionárias responsáveis pela produção daquilo que no campo dos estudos culturais denomina-se de "políticas de identidade". 
O conteúdo desses projetos identitários, todavia, é necessariamente instável, pois o significado dos estereótipos por eles criados não advém unicamente de sua forma, mas, sobretudo, dos usos sociais que deles se desprendem "por baixo". Ocorre que esses olhares "de cima" e "de baixo", o que está "dentro" e o que está "fora" das normas jurídicas que orientam o trabalho nesse ramo da educação especial, são apenas refrações de um mesmo compromisso cultural compartilhado pelos diferentes atores e atrizes que as praticam - para empregar um termo de Karina Kuschnir (2001) - enquanto projetos "conscientemente planejados". Poderíamos deduzir, então, que o que separa a surdez da audição, bem como a deficiência da normalidade, a inclusão da exclusão, não é exatamente o modelo educacional por meio do qual determinada identidade cultural nos é apresentada, mas a utilização efetiva de tal retórica "oficial" na regulação moral de nossas relações cotidianas. O que indica que, embora as ideologias estatais corriqueiramente dividam a realidade social em pares maniqueístas, seduzindo ou coagindo as pessoas a adotarem certas categorias, seu uso é sempre incerto.

\section{Referências}

BERNSTEIN, B. A estruturação do discurso pedagógico: classe, códigos e controle. Petrópolis: Vozes, 1996.

BHABHA, H. O local da cultura. 2. ed. Belo Horizonte: UFMG, 2013.

BOURDIEU, P. A miséria do mundo. Petrópolis: Vozes, 1993.

BRASIL. Presidência da República. Casa Civil. Subchefia para Assuntos Jurídicos. Lei $n^{\circ}$ 10.836, de 9 de janeiro de 2004. Cria o Programa Bolsa Família e dá outras providências. Brasília, 2004. Disponível em: <http://www.planalto.gov.br/ccivil_03/_ ato2004-2006/2004/lei/110.836.htm>. Acesso em: 2 mar. 2017.

BRASIL. Ministério da Educação. Política nacional de educação especial na perspectiva da educação inclusiva. Documento elaborado pelo Grupo de Trabalho nomeado pela Portaria $n^{\circ} 555 / 2007$, prorrogada pela Portaria $n^{\circ} 948 / 2007$, entregue ao Ministro da Educação em 07 de janeiro de 2008. Brasília, 2008. Disponível em: $<$ http://portal.mec.gov.br/arquivos/pdf/politicaeducespecial.pdf $>$. Acesso em: 2 mar. 2017. 
BRASIL. Ministério da Educação. Conselho Nacional de Educação. Câmara de Educação Básica. Resolução nº 4, de 2 de outubro de 2009. Institui Diretrizes Operacionais para o Atendimento Educacional Especializado na Educação Básica, modalidade Educação Especial. Brasília, 2009. Disponível em: <http://portal.mec.gov.br/dmdocuments/rceb004_09.pdf>. Acesso em: 2 mar. 2017.

CARNIEL, F. A invenção (pedagógica) da surdez: sobre a gestão estatal da educação especial na primeira década do século XXI. 2013. Tese (Doutorado em Sociologia Política)-Centro de Filosofia e Ciências Humanas, Universidade Federal de Santa Catarina, Florianópolis, 2013.

GIROUX, H. Atos impuros. Porto Alegre: Artmed, 2003.

HEREDIA, F.; CASAS, G. Nomogénesis. Violencias institucionales y marcadores de la diferenciación social: análisis del proceso de debate, probación y texto de la Ley 10.903 (Ley Agote). Teoria e Cultura, Juiz de Fora, v. 11, n. 3, p. 55-74, abr. 2017. Disponível em: <https://teoriaecultura.ufjf.emnuvens.com.br/TeoriaeCultura/article/ view/2994>. Acesso em: 5 ago. 2017.

HERZFELD, M. Intimidade cultural: poética social no Estado-Nação. Coimbra: Edições 70, 2008.

FOUCAULT, M. Os anormais: curso no Collége de France (1974-1975). São Paulo: Martins Fontes, 2001.

KUSCHNIR, K. Trajetória, projeto e mediação na política. In: VELHO, G.; KUSCHNIR, K. (Org.). Mediação, cultura e política. Rio de Janeiro: Aeroplano, 2001. p. 137-164.

LARROSA, J. Pedagogia profana: danças, piruetas e mascaradas. Belo Horizonte: Autêntica, 2000.

MENDES, E. G. A radicalização do debate sobre inclusão escolar no Brasil. Revista Brasileira de Educação, Rio de Janeiro, v. 11, n. 33, p. 387-405, set./dez. 2006.

MCLAREN, P. Multiculturalismo crítico. São Paulo: Cortez, 1997.

PARANÁ. Secretaria de Estado da Educação. Departamento de Educação Básica. Diretrizes curriculares da educação básica. Curitiba, 2008.

PEIRANO, M. Antropologia política, ciência política e antropologia da política. In: PEIRANO, M. Três ensaios breves. Brasília: UnB, 1997. p. 17-29. (Série Antropologia, 231).

SKLIAR, C. Pedagogia (improvável) da diferença: e se o outro não estivesse aí?. Rio de Janeiro: DP\&A, 2003. 
SILVA, T. T. Identidade e diferença: a perspectiva dos estudos culturais. Petrópolis: Vozes, 2004.

SIMÕES, J. "A gente que está aqui é diferente": notas etnográficas sobre deficiência intelectual numa APAE do interior de São Paulo-BR. Teoria e Cultura, Juiz de Fora, v. 11, n. 3, p. 75-88, abr. 2017. Disponível em: <https://teoriaecultura.ufjf.emnuvens. com.br/TeoriaeCultura/article/view/2995/2307>. Acesso em: 5 ago. 2017.

VIEIRA, R. Etnobiografias e descoberta de si: uma proposta da Antropologia da Educação para a formação de professores para a diversidade cultural. Pro-Posições, Campinas, v. 24, n. 2, p. 109-123, maio/ago. 2013. Disponível em: <http://www.scielo.br/ scielo.php?script=sci_arttext\&pid=S0103-73072013000200009\&lng=en\&nrm=iso >. Acesso em: 5 ago. 2017.

WAGNER, R. A invenção da cultura. São Paulo: Cosac \& Naify, 2010.

WALSH, C. Pedagogías decoloniales: prácticas insurgentes de resistir, (re)existir y (re) vivir. Quito: Abya-Yala, 2013.

Recebido: 10/03/2017 Aceito: 08/08/2017 | Received:3/10/2017 Accepted: 8/8/2017 